\title{
Analysis of HVAC Energy Saving Technology
}

\author{
Yuling Miu \\ Department of Power Engineering, School of Energy, Power and Mechanical Engineering, North China \\ Electric Power University, Baoding, Hebei 071003, PR China \\ 535368209@qq.com.
}

Keywords: HVAC, energy saving, new technology.

\begin{abstract}
This paper mainly analyzes the phenomenon of energy waste in the current HVAC, puts forward the corresponding measures, and introduces the renewable energy system widely used in the world.
\end{abstract}

\section{Preface}

In recent years, building HVAC in the quality of life for the improvement of the quality of life, but also caused a lot of energy consumption in the overall building energy consumption, accounting for building energy consumption 30\% 50\%, and increased year by year. On the other hand, the existing HVAC systems use energy that is essentially high grade non-renewable energy, where electricity consumption accounts for a significant proportion. At the same time, the acceleration of urbanization process and the improvement of people's quality of life, HVAC system can be widely used for HVAC system . So energy consumption will be further increased, which is bound to cause further expansion of energy supply and demand contradictions. China's economy is already an inevitable step in sustainable development, that reduce social energy Consumption and to take energy-saving technology.

\section{The problem HVAC in energy-saving aspects}

\subsection{The irrationality of enclosure structure}

Most of the enclosure structure to take non-warm material in China, doors and windows closed poor. It is very large in total heat loss that the heat transfer loss through the enclosure structure. Such as the Beijing area, through the envelope of the heat loss accounted for $77 \%$ of all heat loss.

\subsection{The promotion of new technologies}

It provides a new direction for energy saving that the new technology is applied in HVAC system. For example, ground source heat pump air conditioning system, solar refrigeration heating system, not only can achieve the effective use of renewable energy, and can bring significant economic benefits, is worthy of promotion. But as with any new technology, these new technologies tend to be high in cost, and there are certain restrictions on the geographical conditions used. Besides there are many areas where there is a need for improvement technically, so it is difficult to implement on a large scale.

\subsection{Public awareness is not high in energy conservation issues}

With the improvement of people's living standards, people are increasingly demanding the comfort. Many people exist the same problems that air conditioning temperature is too low in the summer, the temperature will be too high in winter, which is contrary to the state's "comfortable air-conditioning summer set temperature of not less than $26^{\circ} \mathrm{C}$, winter set the temperature should not be higher than $20^{\circ} \mathrm{C} "$. The greatly increased the building energy consumption.

\section{The measures of solving the problem in HVAC energy conservation}

\subsection{To improve the building envelope insulation performance}

For the HVAC system, it accounts for a significant proportion of the air conditioning load through the enclosure structure. The insulation performance of the envelope determines the size of the integrated heat transfer coefficient of the envelope, and also determines the size of the air conditioning 
load through the enclosure structure. So the first requirement is to improve the thermal insulation performance of retaining structure in the building energy efficiency design specifications and standards issued by the state. Add wall and roof insulation appropriately, can reduce the cold and hot load produced by the palisade structure, so as to achieve the goal of energy saving.

\subsection{Choosing energy-saving way of heating air conditioning}

It is very different in energy consumption and the comfort of the indoor environment by heating of the same object in different heating way. Such as low-temperature radiant floor heating in the north, not only comfortable, and it can lower $2{ }^{\circ} \mathrm{C} \sim 5{ }^{\circ} \mathrm{C}$ that the indoor temperature compared with the radiator way, of course greatly reduced energy consumption. Similarly, choice radiant air conditioning mode generally comfortable and saving energy than the convective way when choosing air conditioning mode.

\subsection{Select renewable or low-grade energy air conditioning system}

The heavy use of non-renewable energy has led to the depletion of energy and the deteriorating environment. It becomes inevitable to develop and utilize natural renewable energy. In natural renewable energy, they has matured of solar energy, wind power, solar heating or refrigeration systems, ground source heat pump air conditioning system technology, should be vigorously promote the use. The use of renewable energy HVAC system, not only has significant environmental and social benefits, but also the most effective way to save energy.

\section{The new technology of saving HVAC energy}

\subsection{Warm recycling equipment}

Waste heat is the normal energy when HVAC operation process. However The design and application of the Warm recycling equipment not only to prevent the spread of the waste heat in the air caused by energy waste, but also effectively improve the warm wind of air conditioning energy utilization rate, so as to achieve the purpose of reducing energy consumption. At present, more than $30 \%$ of the air-conditioning load is the new wind load. Under the premise of the fresh air system to ensure the indoor air circulation and the fresh air level, part of the air will be discharged outdoors, and it is the main wind energy system energy consumption that this process of fresh air energy transmission. Warm recycling equipment can reduce the fresh air load by transfer energy to the fresh air of the application, thus reducing the overall energy consumption of air conditioning and also improve HVAC unit operation load at the same time. It is optimized in the energy conservation and emissions reduction, and efficiency.

\subsection{Variable frequency and variable flow technology of air conditioning water system}

Central air conditioning cooling load changes along with the change of environmental temperature and the usable floor area, water system of the constant flow water system of water pump motor is running at full capacity, basic form large flow phenomenon of small temperature difference.For this low efficiency, energy consumption, you can choose to use air conditioning water system inverter control chilled water pump motor running, so that the flow of chilled water and cold load is proportional to the change, received a good energy saving effect.

\subsection{Ultra-low temperature heat pump technology}

Ultra-low temperature heat pump technology is a new technology developed with the new technology, it can be used in building HVAC projects, and reduce the energy consumption of HVAC, to achieve HVAC energy. At present, the technology has been widely used in the major building HVAC system temperature adjustment facilities, to meet the temperature requirements in the ultra-low temperature weather. For example: when the building temperature reaches minus $20{ }^{\circ} \mathrm{C}$, the ultra-low temperature heat pump technology products can still be used normally, through its own function of the building temperature for effective regulation; related tests show that when the building temperature is minus $10{ }^{\circ} \mathrm{C}$, the use of the technology obtained temperature control efficiency of $20 \%$ higher than the efficiency of the use of air-cooled heat pump unit, both to achieve the role of temperature control, but also to achieve energy conservation, and promote the development of building energy efficiency. 


\section{Renewable energy air conditioning system}

\subsection{Ground source heat pump air conditioning system}

Ground source heat pump air conditioning system is a can be underground shallow thermal energy for energy conversion system, and for HVAC heating and cooling. Ground source heat pump unit system in the summer can be indoor excess heat transferred to the underground shallow for cooling in the winter can be transferred to the shallow space for heating room, the greatest degree of reduction in the use of HVAC cycle to achieve the purpose of energy conservation. It made full use of the characteristics of the groundwater and the underground soil temperature constant all the year round, is a kind of environmental protection, energy saving, "zero pollution", "zero discharge" of air conditioning equipment.

\subsection{Solar air conditioning system}

Solar as the implementation of new energy, has many high-quality features, such as recyclable, no pollution to the environment. By using the sunlight radiation heat energy, the solar energy air conditioning for cooling and heating air conditioning system.

At present, the realization of solar air conditioning mainly rely on the heat of the sun to heat and heat, solar collectors are collected solar water or hot air, and then use hot water or hot air instead of boiler hot water input refrigeration in the refrigeration. Use the solar energy air conditioning, not only to save the electricity consumption, solve the power supply tense situation, and the whole process more clean energy environmental protection.

\subsection{Storage air conditioning}

The main heat and cold storage air conditioning medium is water and ice. At night to open some cooling unit of refrigeration, for energy savings, the shortage of electric power during the day, when using release of melting ice cold quantity, in order to reduce the electricity load during the day, reducing the cost of electricity. This ice-saving energy technology not only provides a lower temperature air conditioning water supply, but also effectively stores the energy, raising the air conditioning temperature difference.

\section{The conclusion}

In the field of air conditioning, comfortable and become a basic subject in today's architecture and design of energy conservation, environmental protection, use of natural energy, reduce the energy load, become the direction of the future architectural design. Reduce building energy consumption has also been a HVAC researchers goal, strive to achieve zero energy consumption, now also has a lot of scholars have made great contributions in this area. At the same time, we should also actively develop new energy, and promote new energy such as solar energy, geothermal energy, and atomic energy.

\section{References}

[1] Wu Pan. HVAC energy saving measures analysis. Symposium on Architecture Technology and Management. Beijing. December 27, 2015, p. 53+29.

[2] Su Wenhui. Introduction to HVAC energy saving problems and advice. Fujian Province HVAC refrigeration academic annual meeting. Fujian. November 25, 2015 p, 231-233.

[3] Guan Xiaoqian. Introduction to building HVAC energy saving optimization design method. Discussion on Energy - saving Optimization Design Method of Building HVAC. Walk. October 2015. p36.

[4] Ren Peng. Modern HVAC technology energy saving analysis. Symposium on Architecture Technology and Management. Beijing. July 27, 2015. p283+341.

[5] Wang Guangqin. Jinan area passive home design experience. The 6th National Conference on Building Environment and Equipment Technology Exchange. Guangzhou. November 11, 2015, p. 282-285. 
[6] Bi Zhiwei. About the exploration of building HVAC energy saving technology analysis. Science 2014 scientific and technological innovation and enterprise management. Beijing. April 19, 2014, p7.

[7] Ge Jing. Theory of the application of environmental protection and energy saving technology in HVAC system. Science - 2014 scientific and technological innovation and enterprise management. Beijing. April 19, 2014, p46.

[8] Lin Haiyan. Residential building energy-saving problem of palisade structure. 2001 China Green Building, International Symposium on Sustainable Development. Beijing. May 30, 2001. p, 102-105. 